\title{
FORMATION OF A FUNCTION SERIES FOR ESTIMATES OF TRANSPORTATION ENERGY EFFICIENCY BASED ON BARTINI'S LT-TABLE ENTITIES
}

Jurij Kotikov

Saint Petersburg State University of Architecture and Civil Engineering

2-ya Krasnoarmeiskaya st., 4, St. Petersburg, Russia

cotikov@mail.ru

\begin{abstract}
A function series for estimates of transportation energy efficiency is formed based on Bartini's LT-table entities. The study represents a follow-up of the method provided by the author to estimate transportation energy efficiency based on the Bartini's L6T-4 entity. The Bartini's LT-table, supplemented by Aleinikov, is adjusted using system representation of the energy series of entities: Energy-Linergy-Arergy-Volergy. Methodical specifics of obtaining transportation energy efficiency estimates for $1 \mathrm{D}, 2 \mathrm{D}$ and $3 \mathrm{D}$ spatial objects are considered. A numerical analysis of transportation in a 2D zone is carried out following a hypothetical example of daily commuting in the Saint Petersburg agglomeration.
\end{abstract}

\author{
Keywords \\ LT-systematization, Bartini's $\mathrm{L}^{\mathrm{m} T} \mathrm{~T}^{-4}$ entities, Energy, Linergy, Arergy, Volergy, megacity, agglomeration.
}

\section{Introduction}

Estimation of transportation and logistics energy intensity is a topical issue (Kotikov, 2006). The issue is becoming more relevant with an increase in movement speed, transportation scale, coverage, as well as with development of new types of vehicles, power plants and fuel (Kotikov, 2006).

Logistics made the way from one-off deliveries to supply chains (4PL) and reached the level of network deliveries (5PL). At this development stage, one of the possible ways of subsequent methodological improvement of the logistics apparatus is mastering methods of transfer from network models to field models. Another way, in the light of developing space and air (Kotikov, 2018; Leonov, 2010) transport, three-dimensional distribution logistics (high-rise warehouse terminals, office and residential skyscrapers, etc.), is development of the optimization modeling of three-dimensional networks and fields.

The listed aspects require to develop methods to estimate energy efficiency of engineering systems in terms of the requirements of the future technological paradigm. In his previous papers, the author of the article used the Bartini's LT-table L6T-4 entity to develop new methods for energy efficiency estimation (Kotikov, 2006, 2017a, 2017b, 2017c). The applicability of the method based on this entity to estimate linear deliveries of cargo was shown.

In this study, a task of developing criteria and techniques for $2 \mathrm{D}$ and $3 \mathrm{D}$ options of distribution logistics based on Bartini's LT-table entities and constructing a function series with dimensionalities ranging from 1D to $3 \mathrm{D}$ is set.

The author's adjustment of several concepts and terms introduced by his predecessors based on Bartini's LTtable entities is deemed to be important.

\section{Method development}

Proceeding from the Maxwell's idea (1873) on the possibility of constructing a system of measurement units based on only two units - length $L$ and time $T$ Bartini systematized and arranged all physical values in 


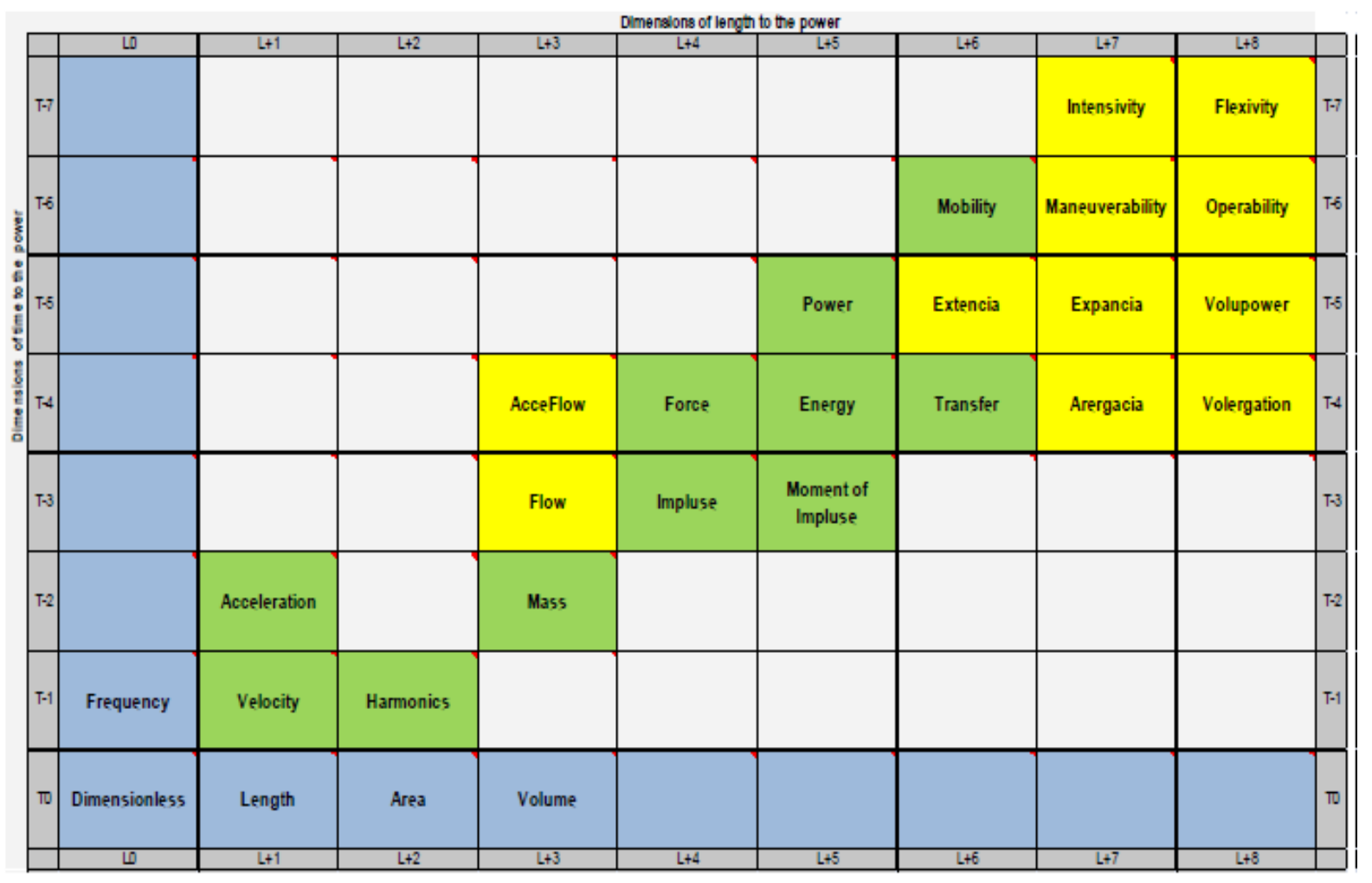

Figure 1. Matrix of physical laws and measurements

powers of $\mathrm{L}^{\mathrm{m}}$ and $\mathrm{T}^{-\mathrm{n}}$ in a special LT-table (Bartini, 1965). Let us specify the dimensionality of the following standard kinematic quantities in L-T coordinates: length $-L^{1} T^{0}$; mass $-\mathrm{L}^{3} \mathrm{~T}^{-2}$; energy $-\mathrm{L}^{5} \mathrm{~T}^{-4}$; moment of mass $-\mathrm{L}^{4} \mathrm{~T}^{-2}, \mathrm{~m}^{4}$ / $\mathrm{s}^{2}$ (in accepted units of transport work, $\mathrm{t} \cdot \mathrm{km}$, through the conversion coefficient). In collaboration with Kuznetsov, Bartini suggested a quantity with dimensionality $\mathrm{L}^{6} \mathrm{~T}^{-4}, \mathrm{~m}^{6} /$ $\mathrm{s}^{4}$, representing transmission of energy over a distance (Transfer) (Bartini, 1974). Later Obraztsova and Kuznetsov (Obraztsova, 1997) suggested a name for the transport version of this unit: "Tran" with dimensionality $\left[\mathrm{L}^{6} \mathrm{~T}^{-4}\right]=$ $(\mathrm{t} \cdot \mathrm{km}) \cdot \mathrm{km}^{2} / \mathrm{h}^{2}$.

In 2006-2011, Aleinikov, in collaboration with his US scientific team, filled 11 empty cells of the Bartini's LTtable with the corresponding peer entities and developed physical laws for the conservation of those entities. After the addition of those entities, the original Bartini's LT-table took on a form depicted in Figure 1 (Aleinikov, 2011). The table cells filled with the above-mentioned 11 new entities are colored in yellow.

Since 2001, the elaboration of the methodological approach to the estimation of transport and transportation energy efficiency, considering the squared delivery velocity, has been associated with the development of Bartini's ideas on geometric LT-systematization of physics laws, as well as ideas of Obraztsova and Kuznetsov (Kotikov, 2001).

Several author's studies (Kotikov, 2006, 2017a, 2017b, 2017c) show that the vehicle output and energy consumption should be brought into correlation with each

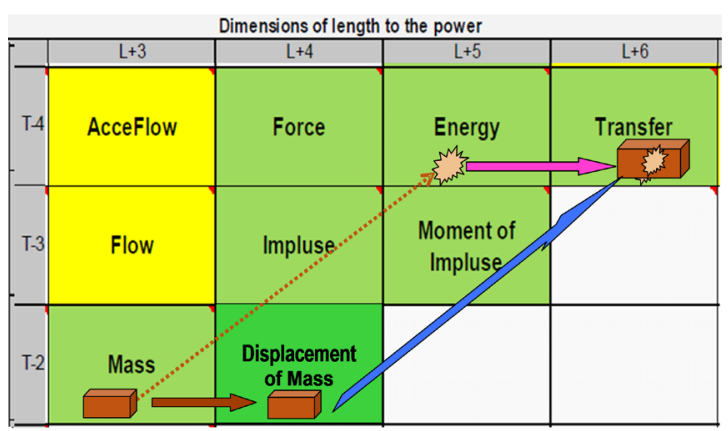

Figure 2. A diagram of output and energy consumption correlation at the level of the Transfer entity on the Bartini-Aleinikov's LT-table canvas (Kotikov, 2017a)

other (to obtain a dimensionless efficiency coefficient) at the level of the Transfer entity in the L6T-4 cell.

The author also points out that it is necessary to multiply the output (formed in the L4T-2 cell) by the squared velocity of cargo transfer, which corresponds to the diagonal transition within the table by two levels to the right and up: see a Bartini-Aleinikov's LT-table canvas fragment in Figure 2.

Identification of method variables and indicators according to the diagram in Figure 2 is given in Table 1. Let us note that the Linear transport work (Output $W_{1}$ ) and Linear transport service $S_{1}$ in this loop (see arrows in Figure 2) are taken with index ",", which means D1 dimensionality and point-like nature of a serviced spatial object. 
Table 1. Identification of method variables and indicators according to the diagram in Figure 2

\begin{tabular}{|l|l|l|l|l|}
\hline & $L^{3}$ & $L^{4}$ & $L^{5}$ & $L^{6}$ \\
\hline$T^{-4}$ & & Force, $\mathrm{N}$ & $\begin{array}{l}\text { Energy } \\
E, \mathrm{~J}\end{array}$ & $\begin{array}{l}\text { Transfer, } \\
\text { Trn (Linear } \\
\text { transport } \\
\text { service } S_{1}, \\
\left.\mathrm{t} \cdot \mathrm{km}^{3} / \mathrm{h}^{2}\right)\end{array}$ \\
\hline$T^{-3}$ & & Impulse & $\begin{array}{l}\text { Moment of } \\
\text { impulse }\end{array}$ & \\
\hline$T^{-2}$ & $\begin{array}{l}\text { Mass, } \mathrm{m}^{3} / \\
\mathrm{s}^{2}(\text { Mass } \\
M, t)\end{array}$ & $\begin{array}{l}\text { Moment } \\
\text { of mass } \\
\text { (Linear } \\
\text { transport } \\
\text { work (Out- } \\
\left.\text { put } W_{1}\right), \\
\mathrm{t} \cdot \mathrm{km})\end{array}$ & & \\
\hline
\end{tabular}

Further development of the methodology is construction of a series of estimates for spatial spheres' servicing based on Bartini's LT-table entities

In author's studies (Kotikov, 2001, 2006, 2017a, 2017b, 2017c), a methodology for energy efficiency estimation regarding vehicles and means of transport upon linear transportation (over the network) of transportation objects, with account for cumulative energy consumption during the life cycle of vehicles, was formed.

However, in areas with high business activity and the large number of goods and people, the pattern of distribution is as if "blurred" by the law of large numbers, smoothed down, switching from the network configuration to the field one. Some other transport phenomena also have field character: dispersion of exhaust gases over the area; noise fields; irrigation of agricultural fields, fire areas, etc. Visualization of transition from the network model to the field model is shown in Figure 3.

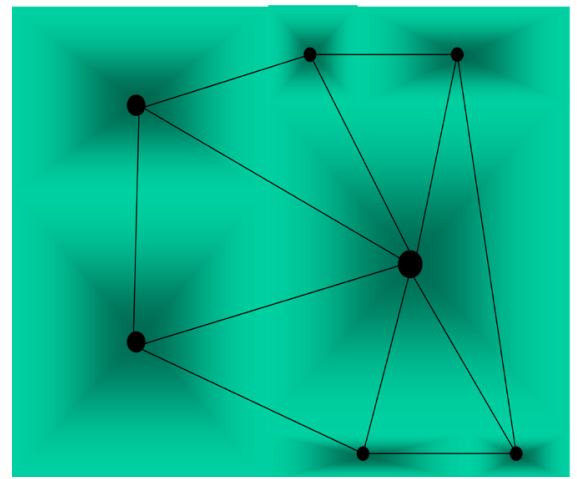

Figure 3. Transition from the network model to the field model

A similar picture becomes more and more relevant in a three-dimensional version: e.g. dispersion of exhaust gases in the volume over the city, coal heaping in open terminals, distribution of people in the $3 \mathrm{D}$ volume of a skyscraper (up to 10 thousand people in dozens of skyscrapers in Shanghai), etc.
By analogy with the linear case, when the author used the Bartini's LT-table Transfer L6T-4 criterion (see Table 1) to estimate cargo transportation energy efficiency, we will develop criteria for cases of utilizing the energy spent on transportation, upon the area (2D) and volume (3D) distribution of goods and/or people massifs.

For this purpose, let us use the Bartini-Aleinikov's matrix (Figure 1). Let us select the $\{\mathrm{L} 3-\mathrm{L} 8 ; \mathrm{T}-2-\mathrm{T}-4\}$ fragment. As it was shown previously (Kotikov, 2017a, 2017b, 2017c), in case of linear transportation of cargo/ people to a delivery/destination point, the Transfer entity (table cell) was used for the concentration of service $S_{1}$ and corresponding energy consumption Trn. In the energy layer of entities (T-4 row), it is the following product: Energy $\times \mathrm{L}=$ Transfer (L6T-4 entity).

In case of cargo/people distribution throughout the area of delivery, it will be required to multiply the energy consumed by $L^{2}$. It is Arergacia $=$ Energy $\times L \times L(L 7 T$ 4 entity) on the Bartini-Aleinikov's canvas (Figure 1) (in another article, Aleinikov uses the Arergation term).

In case of cargo/people distribution throughout the volume of delivery, it will be required to multiply the energy consumed by $L^{3}$. It is Volergation $=$ Energy $\times L \times L \times L$ (L8T-4 entity) on the Bartini-Aleinikov's canvas (Figure 1).

Let us specify characteristics of new concepts (Arergation (Arergacia) and Volergation) in the form suggested by Aleinikov in 2007 (Aleinikov, 2007).

The Arergation entity (derived from area + ergon) represents area distribution of energy. Its measurement unit is Sergal. The Law of Arergation Conservation has the following form:

Arg $=\operatorname{Trn} \times \mathrm{L}=\mathrm{L} 7 \mathrm{~T}-4=$ const;

1Sergal $=1$ Tran $\times 1 \mathrm{~m}=1 \mathrm{~J} \times 1 \mathrm{~m}^{2}$.

The Volergation entity (derived from volume + ergon) represents volumetric distribution of energy. Its measurement unit is Natal. The Law of Volergation Conservation has the following form:

$\mathrm{Vrg}=\mathrm{Arg} \times \mathrm{L}=\mathrm{Trn} \times \mathrm{L} 2=\mathrm{L} 8 \mathrm{~T}-4=$ const;

1 Natal $=1$ Sergal $\times 1 \mathrm{~m}=1 \operatorname{Tran} \times 1 \mathrm{~m}^{2}=1 \mathrm{~J} \times 1 \mathrm{~m}^{3}$.

This is a powerful scientific innovation. However, the following critical remark can be made (which in no way derogates from the merits of the Aleinikov's school): the names of entities are non-systematic. Moreover, Aleinikov even used people's names for measurement units. To construct a series, a systematic approach is preferable even in name creation. Let us try to perform this task.

Let us assign to the entities of the energy series (elements of the Bartini's LT-table T-4 row) names consonant with the Energy term (where the -gy particle carries the general meaning of the entity):

- let us replace Transfer with Linergy (derived from linear + ergon);

- let us replace Arergation (also known as Arergacia) with Arergy (derived from area + ergon);

- let us replace Volergation with Volergy (derived from volume + ergon).

Using the above, we can build a diagram (see Figure 4) on the Bartini's LT-table canvas. 


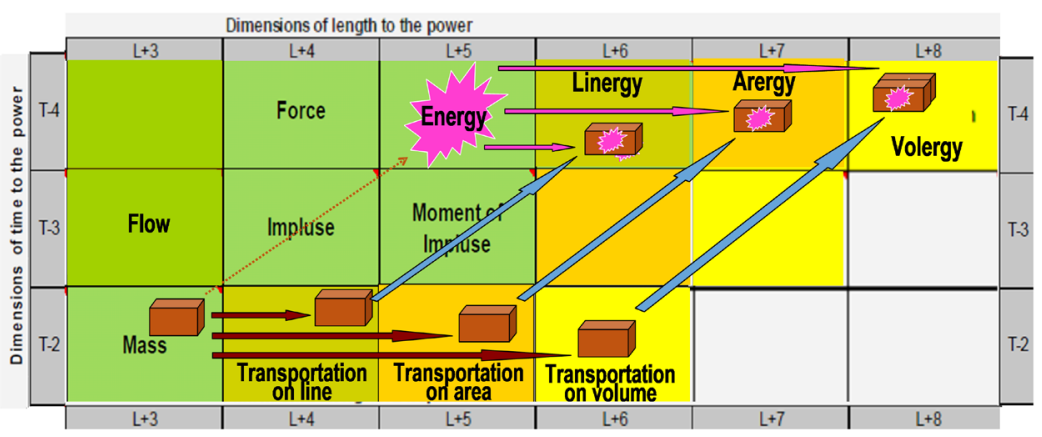

Figure 4. A new toponymy of entities and connection between them

Besides, we will use the -ation suffix (used in English for the formation of verbal nouns with process meaning) to identify the corresponding transfer processes (similar to the Transport-Transportation pair of related concepts):

- for linear transfer of energy - Linergation;

- for energy distribution throughout a 2D area - Arergation;

- for energy distribution throughout a 3D sphere - Volergation.

It is presented in Figure 5 which can be considered a detailed elaboration of the diagram in Figure 4. Loops $1,2,3$ in the corresponding table cells compare energy consumption for an idealized cargo transfer with the actual reduced energy consumption of the transportation system (see the methodology suggested by the author (Kotikov, 2017c)).

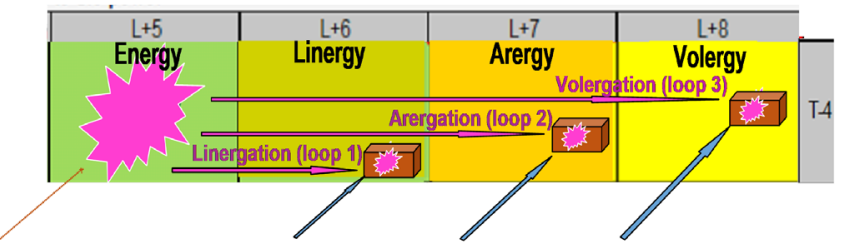

Figure 5. Detailed elaboration of Bartini's LT-table T-4 energy series concepts

Notations of quantities representing entities (similar to how $A, E$, or $W$ represent the entity of Energy) are as follows:

for Linergy: Lrg with measurement unit Jm1 (derived from $\left.J \times m^{1}\right)$;

for Arergy: Arg with measurement unit Jm2 (derived from $\left.J \times m^{2}\right)$;

for Volergy: Vrg with measurement unit Jm3 (derived from $J \times m^{3}$ ).

Identification of new method variables and indicators according to the diagram in Figure 4 is given in Table 2 .
Table 2. Identification of method variables and indicators according to the diagrams in Figures 4 and 5.

\begin{tabular}{|c|c|c|c|c|c|c|}
\hline & $L^{3}$ & $L^{4}$ & $L^{5}$ & $L^{6}$ & $L^{7}$ & $L^{8}$ \\
\hline$T^{-4}$ & & $\begin{array}{l}\text { Force, } \\
\mathrm{N}\end{array}$ & $\begin{array}{l}\text { Energy } \\
E, \mathrm{~J}\end{array}$ & $\begin{array}{l}\text { Liner- } \\
\text { gy, Lrg } \\
\text { (Linear } \\
\text { transport } \\
\text { service } \\
\mathrm{S} 1, \\
\mathrm{t} \cdot \mathrm{km}^{3} / \mathrm{h}^{2} \text { ) }\end{array}$ & $\begin{array}{l}\text { Arergy, } \\
\text { Arg } \\
\text { (Trans- } \\
\text { port } \\
\text { service } \\
\text { of area } \\
\text { distribu- } \\
\text { tion } S_{2} \text {, } \\
\mathrm{t} \cdot \mathrm{km}^{4} / \mathrm{h}^{2} \text { ) }\end{array}$ & $\begin{array}{l}\text { Voler- } \\
\text { gy, Vrg } \\
\text { (Trans- } \\
\text { port } \\
\text { service } \\
\text { of vol- } \\
\text { umetric } \\
\text { distribu- } \\
\text { tion } S_{3}, \\
\mathrm{t} \cdot \mathrm{km}^{5} / \mathrm{h}^{2} \text { ) }\end{array}$ \\
\hline$T^{-3}$ & & Impulse & $\begin{array}{l}\text { Moment } \\
\text { of im- } \\
\text { pulse }\end{array}$ & & & \\
\hline$T^{-2}$ & $\begin{array}{l}\text { Mass, } \\
\mathrm{m}^{3} / \mathrm{s}^{2} \\
(\text { Mass } \\
M, \mathrm{t})\end{array}$ & $\begin{array}{l}\text { Linear } \\
\text { trans- } \\
\text { port } \\
\text { work } \\
\text { (Output } \\
W_{1} \text { ), } \\
\mathrm{t} \cdot \mathrm{km}\end{array}$ & $\begin{array}{l}\text { Trans- } \\
\text { port } \\
\text { work } \\
\text { through- } \\
\text { out area } \\
\text { (Output } \\
\left.W_{2}\right) \\
\mathrm{t} \cdot \mathrm{km}^{2} \text { ) }\end{array}$ & $\begin{array}{l}\text { Transport } \\
\text { work } \\
\text { through- } \\
\text { out } \\
\text { volume } \\
\text { (Output } \\
W_{3} \text { ), } \\
\mathrm{t} \cdot \mathrm{km}^{3} \text { ) }\end{array}$ & & \\
\hline
\end{tabular}

\section{Case Study}

Let us give an example of calculation for twodimensional distribution of transport work throughout the area (with regard to transportation in the megacity territory).

For a start, let us consider a simple analogy - area irrigation with a sprinkler with one sprayer (see Figure 6) (Frolova, 2017). The service of water distribution throughout the area of sprinkler coverage S2 consists in supplying a mass of water with a certain supply rate and more or less uniform distribution of this mass over the service area. 
If we refer to the sprinkler, then its Arergy is the energy spent by the system of water supply to deliver it to the nozzle and spray, multiplied by the spraying area. The service rendered by the system under consideration consists in area irrigation. This service is proportionate to the area serviced. That is why in this case the area is rightfully included into the Arergy criterion as a multiplier.

The scheme can be complicated by various sprinkler options and their systems (stationary sprinklers with multiple sprayers; single mobile sprinklers; systems of mobile sprinklers) providing both grid and contour irrigation (when irrigation is carried out using mobile

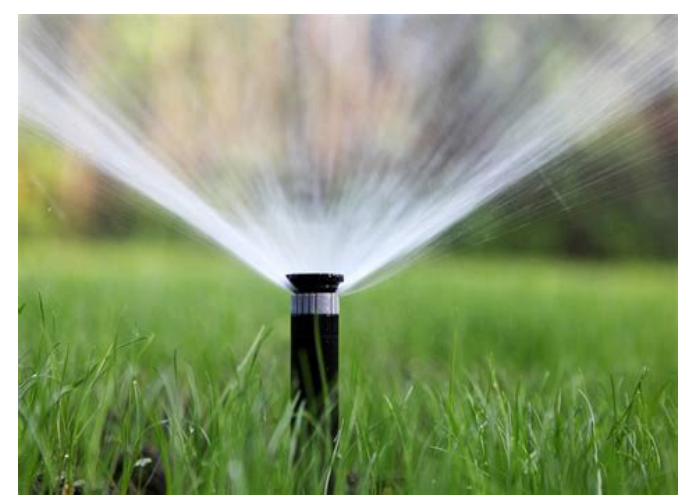

Figure 6. Field character of water distribution using a stationary sprinkler with one sprayer

devices moving only along the perimeter road (see Figure 7)) (Frolova, 2017). This latter option can be used as an analogue for the megacity issue.

Let us note here that in all cases water (agent) is taken from some source (resource), and the calculation of Arergy should account for cumulative energy consumption not only for the actual spraying, but also for the operation of mobile devices, provision of water resources in the source (a canal, a reservoir), or, more precisely, energy consumption in the entire irrigation system.

The scheme under consideration can be easily applied to transportation and logistics in a zone or region. The simplest cases are production points, distribution centers, etc. But in case of production and distribution networks, point sources located at network nodes, jointly serve the territory by analogy with spraying (irrigation). Transportation in a city when importing the mass of commodities along outbound routes can be given as an example.
Let us return to Table 2. Linear transport output $W_{1}$ represents standard transport work in $\mathrm{t} \cdot \mathrm{km}$.

Similarly, to bring the output for the area served $W_{2}$ (see Table 2) in correlation with the corresponding energy consumption, we multiply it by the squared velocity of cargo transfer; this corresponds to the diagonal transition within the table from the L5T-2 cell by two levels to the right and up - to the cell of the Arergy L7T-4 entity (Table 2).

Let us consider a hypothetical numerical example. The Leningrad Region represents a source of daily commuting for the core of the Saint Petersburg agglomeration. Let us accept the ground part of the administrative area of Saint Petersburg with an area of approximately $900 \mathrm{~km}^{2}$ as this core.

This area is filled with industrial enterprises, educational institutions, trade enterprises and other places of visit. Although people move within the city network, let us "blur the network to make it seem like a field" (see Figure 3) and accept input flow distribution within the agglomeration core to be uniform.

Electric trains of the Saint Petersburg railway junction carry 80 million people per year. Let us assume that half of them - 40 million - are those who commute daily. The average train speed is $60 \mathrm{~km} / \mathrm{h}$. The average trip length is $60 \mathrm{~km}$, i.e. the average time per a trip is 1 hour.

Annual transport work in the area (Area output $W_{2}$ ) is equal to:

$W_{2}=40,000,000$ passengers $\times 900 \mathrm{~km}^{2}=36 \cdot 10^{9}$ pass$\mathrm{km}^{2}=36 \cdot 10^{15}$ pass $-\mathrm{m}^{2}$.

Area transport service:

$S_{2}=W_{2} \times V^{2}=36 \cdot 10^{9}$ pass $-\mathrm{km}^{2} \times 60^{2} \mathrm{~km}^{2} / \mathrm{h}^{2}=1,296 \cdot 10^{11}$ pass $\cdot \mathrm{km}^{4} / \mathrm{h}^{2}=1,296 \cdot 10^{11}$ pass $\cdot \mathrm{km}^{4} / \mathrm{h}^{2}=36 \cdot 10^{15}$ pass $-\mathrm{m}^{2} \times$ $(60 / 3.6)^{2} \mathrm{~m}^{2} / \mathrm{s}^{2}=36 \cdot 10^{15} \times 277.777=10,000 \cdot 10^{15}$ pass $\cdot \mathrm{m}^{4} /$ $\mathrm{s}^{2}$.

Despite the fact that servicing of passenger flows is different from servicing of cargo flows, we will additionally calculate the mass characteristic of the passenger flow. Taking a ratio of 1 ton $\approx 14$ people (i.e. the person's mass is $71.43 \mathrm{~kg}$ ), we can calculate the mass equivalent of the area transport service:

$S_{2}=10^{19}$ pass $\cdot \mathrm{m}^{4} / \mathrm{s}^{2} \times 71.43 \mathrm{~kg} /$ pass $=71.43 \cdot 10^{19}$ $\mathrm{m}^{2} \cdot\left(\mathrm{kg} \cdot \mathrm{m}^{2} / \mathrm{s}^{2}\right)=0.7143 \cdot 10^{21} \mathrm{Jm} 2$.

Let us calculate energy consumption. One carriage has 100 seats. Usually, trains have $4-12$ carriages. Let us take 8 carriages, i.e. 800 passengers per one train. The hourly power of an electric drive of a train having 8 carriages amounts to $3,200 \mathrm{~kW}$ (SCBIST, 2018). In order
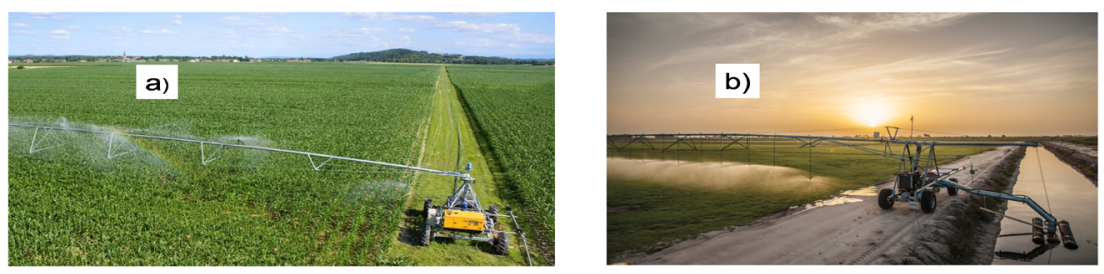

Figure 7. Contour irrigation: a) intermittent; b) continuous 
to transport 40 million passengers, we need 40 million passengers $/ 800$ passengers $/$ train $=50,000$ train trips, one hour each.

Total energy consumption: $3,200 \mathrm{~kW} \times 50,000 \mathrm{~h}=$ $160,000,000 \mathrm{~kW} \cdot \mathrm{h}=16 \cdot 10^{7} \mathrm{kWh} \times 3,600 \mathrm{~kJ} / \mathrm{kW} \cdot \mathrm{h}=576 \cdot 10^{9}$ $\mathrm{kJ}=576 \cdot 10^{12} \mathrm{~J}$.

Transfer of this energy to the serviced area (transition from the L5T-4 cell to the L7T-4 cell, i.e. transition from the Energy entity to the Arergy entity) can be presented as follows:

Arg $=576 \cdot 10^{12} \mathrm{~J} \times 900,000,000 \mathrm{~m}^{2}=518.4 \cdot 10^{21} \mathrm{Jm} 2$.

Now, having two indicators $\left(S_{2}\right.$ and $\left.A r g\right)$ for the L7T-4 cell of the Bartini's LT-table, we can determine the weight coefficient of energy efficiency regarding transport service in the agglomeration core by the mass of daily commuting:

$\eta_{\text {Arg }}=S_{2} / \operatorname{Arg}=0.7143 \cdot 10^{21} \mathrm{Jm} 2 / 518.4 \cdot 10^{21} \mathrm{Jm} 2=$ $0.00138=0.14 \%$.

We should note that the equivalence of dimensions (Jm2) made it possible to calculate the dimensionless coefficient of energy efficiency. This will be rather convenient when comparing different options in optimization calculations for similar systems.

We should also note the very low value of the energy efficiency coefficient obtained. This can be explained by expectations of comfort during passenger transportation, and not by the mass density of the train load (in case of cargo transportation, instead of passengers, with full load of carriages, the $\eta_{\text {Arg }}$ indicator would increase by 14 times). The mass density of the load will have a linear influence on the coefficient. At the same time, the delivery speed will have a quadratic influence: this will allow to estimate the Linergy (L6T-4) and Arergy (L7T-4) criteria.

\section{Conclusion}

Perhaps, the Arergy entity, the L7T-4 element of the Bartini's LT-table, for the first time has found its analytical application for calculating energy efficiency of transport services in the economic area - the core of the megacity agglomeration. The nature of quantitative estimation in the example is rather conventional.

However, in the author's opinion, the created method of territory servicing estimation is viable and subject to further development.

The author of this article is aware that he does not create any new entities. He is just confident in the fact that reformatting of unsteady concepts created by the predecessors will make it possible to construct and analyze future analytical models in the activity field under consideration in more transparent and understandable ways. 


\section{References}

Aleinikov, A. (2007). Nine new laws of conservation: future science horizons. In: Proceedings of the Allied Academies International Conference, 6 (2), pp. 5-10.

Aleinikov, A., Smarsh, D. (2011). 11 new laws of conservation: expanding physics horizons for strategic management. In: Proceedings of the Allied Academies' Internet Conference, 13, pp. 130-131. Available at: http://www.alliedacademies.org/pdfs/ Internet_Proceedings_Vol_13_2011.pdf (accessed on: 30.06.2018)

Bartini, R.O. (1965). Some relations between physical constants. Reports of the Academy of Sciences of the USSR, 163 (4), pp. 861-864.

Bartini, R.O., Kuznetsov, P.G. (1974). Multiplicity in geometries and physics. In: Proceedings of the seminar "Cybernetics of electric power systems", p. 11. Available at: http://www.metodolog.ru/01380/01380.html (accessed on: 30.06.2018)

Frolova, L. (2017). Sprinkler devices: types and application. Available at: http://fb.ru/article/364163/dojdevalnyie-ustanovki-vidyi-primenenie (accessed on: 30.06.2018)

Kotikov, Ju.G. (2001). Osnovy sistemnogo analiza transportnykh sistem [Fundamentals of system analysis for transport systems]. Saint Petersburg: Saint Petersburg State University of Architecture and Civil Engineering, p. 264. (in Russian)

Kotikov, Ju.G., Lozhkin, V.N. (2006). Transportnaya energetika [Transport power engineering]. Moscow: Academia Publishing Center, p. 272. (in Russian)

Kotikov, Ju.G. (2017a). Estimation of transportation energy efficiency by Bartini criterion L6T-4. Architecture and Engineering, 2 (2), pp. 15-19. DOI: 10.23968/2500-0055-2017-2-2-15-19.

Kotikov, Ju.G. (2017b). Calculation of freight rail transport energy efficiency by Bartini criterion L6T-4. Architecture and Engineering, 2 (3), pp. 21-25. DOI: 10.23968/2500-0055-2017-2-3-21-25.

Kotikov, Ju.G. (2017c). Transport energy efficiency assessment on the basis of the life cycle with the attraction of the Bartini Transfer entity. Architecture and Engineering, 2 (4), pp. 21-25. DOI: 10.23968/2500-0055-2017-2-4-14-19.

Kotikov, Ju.G. (2018). Stages of quantomobile development. Architecture and Engineering, 3 (2), pp. 26-35. DOI: 10.23968/2500-0055-2018-3-2-26-35.

Leonov, V.S. (2010). Quantum energetics. Volume 1. Theory of Superunification. Cambridge: Cambridge International Science Publishing, p. 745.

Obraztsova, R.I., Kuznetsov, P.G., Pshenichnikov, S.B. (1997). Inzhenerno-ekonomicheskii analiz transportnykhsistem [Engineering and economic analysis of transport systems]. Novosibirsk, p. 156. Available at: http://lib.uni-dubna.ru/search/files/ur_enjekan/ ur_enj-ek-an.htm (accessed on: 30.06.2018) (in Russian)

SCBIST (2018). Electric trains. FEATURES OF THEIR WORK AND THE DESIGN. Available at: http://scbist.com/zheldor/elektrovoz/elektrovoz_44.html (accessed on: 30.06.2018) 